\title{
¿Código de Ética o Constitución Moral?
}

El Presidente de la República Mexicana Andrés Manuel López Obrador, elegido para el periodo del $1^{\circ}$ de diciembre de 2018 al 30 de noviembre de 2024, retomó un añejo propósito de dar a conocer La Cartilla Moral redactada por Alfonso Reyes en 1952 en los tiempos en que Jaime Torres Bodett fue Secretario de Educación, bajo el mandato del presidente Manuel Ávila Camacho.

Tal propósito tuvo un intento fallido en 1992 cuando bajo la presidencia de Carlos Salinas de Gortari fue adaptada por José Luis Martínez y editada con un tiraje de 700 mil ejemplares, los cuales no se entregaron a los destinatarios por la oposición manifiesta de grupos organizados que criticaron que se promoviera una moral determinada por el propio Estado.

En ésta ocasión, hace unos meses, el presidente López Obrador las entregó en un acto público frente a adultos mayores y además anunció una reimpresión de 8.5 millones de cartillas, las cuales se entregarán a los mexicanos argumentando su necesidad debido a la "decadencia, corrupción, falta de oportunidades y la perdida de valores morales, culturales y espirituales” según lo señaló.

Además anuncio que tal iniciativa formará parte y servirá de modelo para la creación de una Constitución Moral, para lo cual conformó un comité, integrado por Verónica Velasco, José Agustín Ortíz Pinchetti y Enrique Galván Ochoa.

También se dijo que estaría abierta una convocatoria para que los ciudadanos participen de manera individual o colectiva con un texto de máximo cuatro cuartillas cuya recepción inició el 3 de diciembre y culminará el 30 de abril de 2019.

La Cartilla Moral es un breve texto en formato de decálogo que contiene reflexiones sobre aspectos trascendentales para la vida, como lo son, la educación, el bien, el alma, la civilización, la cultura, la familia, la sociedad, la ley, el derecho, la patria, la naturaleza y la moral. 
Destaco el siguiente párrafo: "En torno al círculo del respeto familiar, se extiende el círculo del respeto a mi sociedad. Y lo que se dice de mi sociedad, puede decirse del círculo más vasto de la sociedad humana en general. Mi respeto a la sociedad, y el de cada uno de sus miembros para los demás, es lo que hace posible la convivencia de los seres humanos".

Entiendo que el autor habla del derecho humano consagrado en nuestra constitución y reconocido por tratados internacionales, el derecho humano a ser parte integrante de la sociedad, en donde se configura una integración de lo local en lo global y éste último, trasciende a lo local.

Es así, que a lo largo del texto de la Cartilla Moral se desarrollan conceptos de derechos económicos, sociales, culturales y ambientales, nos habla de dignidad humana, de progreso y de bienestar social, conceptos todos con los cuales, coincidimos en que requerimos acercarlos a nuestro dialogo cotidiano y de cada uno de los ciudadanos; resulta inaplazable reconocernos como mexicanos, enmendar el rumbo, salir de la corrupción que nos ahoga y de la impunidad que nos consume.

Podríamos pensar quizás, que la situación de la sociedad mexicana actual no es tan diferente a la de las décadas 50's y 90's, en las que se pretendió encontrar en La Cartilla Moral un soporte para encausar los valores en la sociedad. Esa podría ser una lectura y por eso la necesidad de transmitir mediante un decálogo un sentir de honestidad y ética social, debido a su ausencia.

Sin embargo, podemos dar otra lectura: Pensar que su creación original por la Secretaría de Educación Pública en 1950 es lo trascendente, quedando de manifiesto que es en la educación en donde encontraremos los cimientos en los cuales podemos construir personalidades fuertes y democráticas.

La educación en todos sus niveles, pre-escolar, primaria, secundaria, bachillerato, licenciatura y posgrado moldea el carácter, forma la personalidad y da el sentido de vida a los hombres y mujeres del México que queremos alcanzar. 
En definitiva, es a través de la educación que se transmiten los valores éticos, sociales, culturales, y hasta ideológicos en sociedad; es así como solo podremos alcanzar sociedades altamente desarrolladas mediante individuos con gran desarrollo biopsicosocial.

En efecto, formamos mediante la educación a los ciudadanos de bien que participarán en la sociedad, competirán y se relacionarán con sus iguales. En tal sentido, la reflexión quizá deba enfocarse a qué tipo de educación estamos dando a los mexicanos, por qué necesitamos hablar en un Estado de Derecho de una Constitución Moral?. Por qué no decidimos re imprimir la Constitución y entregarla a todos los niños de primaria -con edición adaptada para tales edadesa los jóvenes de secundaria, preparatoria, licenciatura y posgrado.

Hablar de derechos humanos hoy en día es un propósito universal; la dignidad humana no debe exponerse bajo ningún motivo o circunstancia, ya que vivimos en un Estado de Derecho, su regulación se da en las leyes, precisamente armonizadas por la Constitución; pero necesitamos ciudadanos que no practiquen la corrupción, instituciones que no se corrompan, administración de justicia que no genere y contribuya con la impunidad, y un sólido consenso en favor de la legitimidad.

Sin embargo, de acuerdo estamos en que no basta las instituciones para dotar de principios democráticos a las sociedades, todas ellas son creadas con tal fin y además lograr el bien común, pero es necesario incidir en las personas para formar ciudadanos de bien y eso solo se logra a través de la educación sustentada en principios universales y democráticos.

La ruta es la educación. Que sea pública, gratuita, de calidad, laica, obligatoria y que contribuya a desarrollar armónicamente todas las facultades del ser humano a través del amor a la Patria, el respeto a los derechos humanos 
y conciencia de solidaridad internacional, en la independencia y en la justicia, tal como reza el artículo tercero constitucional.

En efecto, ya lo apuntó Alfonso Reyes en su Cartilla Moral: La ley no es una imposición ni una restricción contra el libre albedrío, sino, por el contrario, una garantía de libertad. La forma misma del Estado, la Constitución, que es la ley de todas las demás leyes, se considera como emanación de la voluntad del pueblo en la doctrina democrática.

Invierno 2019

Dra. Silvia Patricia López González

Directora-Editora 